Available online on 15.01.2021 at http://ujpr.org
Universal Journal of Pharmaceutical Research
An International Peer Reviewed Journal
Open access to Pharmaceutical research is an open access article distributed under the terms of the Creative Commons Attribution-Non
Commercial Share Alike 4.0 License which permits unrestricted non commercial use,
provided the original work is properly cited
Volume 5, Issue 6, 2020

\title{
ASSOCIATION BETWEEN THE STREPTOCOCCUS MUTANS BIOFILM FORMATION AND DENTAL CARIES EXPERIENCE AND ANTIBIOTICS RESISTANCE IN ADULT FEMALES
}

Abdalhaq Hussin Alhasani ${ }^{1}{ }^{\oplus}$, Ramy Abdulrhman Ishag ${ }^{2}{ }^{\oplus}$, Ameen Abdullah Yahya Al-Akwa $^{2}{ }^{\circ}$, Hassan Abdul wahab Al Shamahy ${ }^{3}$, Mohammed A Al-labani ${ }^{2}$ ib

${ }^{I}$ Orthodontics, Pedodontics and Prevention Department Faculty of Dentistry, Ibb University, Yemen.

${ }^{2}$ Orthodontics, Pedodontics and Prevention Department Faculty of Dentistry, Sana'a University, Yemen. ${ }^{3}$ Departement of Basic Sciences, Faculty of Dentistry, Sana' a University, Republic of Yemen.

\section{ABSTRACT}

Objectives: The aim of this study was to consider the potential association between the formation of salivary streptococcus biofilms and the incidence of caries, as well as with the occurrence of antibiotic resistance among adult mothers in Sana'a, Yemen. Study design: A total of $261 ; 25-35$ year old females were chosen. Clinical examination of females were performed to estimate dental caries experience with the Silness-Loe index, as well as stimulated saliva were collected to assess biofilm production by the phenotypic method i.e. Tissue culture palate methods (TCPM). Finally, antibiogram susceptibility pattern of isolated $S$. mutans was done by Kirby-Bauer disc diffusion method for $6 \beta$-Lactam antibiotics (ampicillin, penicillin, amoxicillin, cefotaxime, methicillin and cefazolin) and 4 non $\beta$-Lactam antibiotics (clindamycin, erythromycin, lincomycin and vancomycin).

Results: When isolated $S$. mutans were exposed to biofilm detection by TCP method, $31(12.2 \%)$ showed high biofilm formation capacity, 46 (18\%) showed moderate biofilm formation capacity, while $184(72.2 \%)$ showed non/weak formation capacity of biofilm. The overall rate of biofilm formation was $30.2 \%$. There was an escalation in the rate of formation of $S$. mutans biofilms with an increased degree of caries index. The $S$. mutans biofilms positve showed a higher rate of resistance than non/weak biofilm formation e.g. ampicillin $(28.6 \%$ versus $12.9 \%, p=0.002)$, amoxicillin $(77.9 \%$ versus $18 \%, p<0.0001)$, and penicillin $(79.2 \%$ versus $23 \%,<0.0001)$ etc.

Conclusion: The present study proved that $S$. mutans is still the major bacteria isolate from the oral cavity, but few persons might not have significant number of $S$. mutans in oral cavity. The $S$. mutans biofilm - producers were more able to cause dental caries compared to the $S$. mutans biofilm-non-producers. Drug resistant factor in the $S$. mutans isolates was found to be associated with $S$. mutans biofilm formation.

Keywords: Adult females, antibiotic resistance, biofilm formation, dental caries; oral cavity, saliva; Streptococcus mutans.

Article Info: Received 12 November 2020; Revised 20 December; Accepted 5 January 2021, Available online 15 January 2021

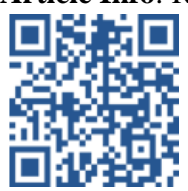
Cite this article-

Alhasani AH, Ishag RA, Yahya Al-Akwa AY, Al Shamahy HA, Al-labani MA. Association between the Streptococcus mutans biofilm formation and dental caries experience and antibiotics resistance in adult females. Universal Journal of Pharmaceutical Research 2020; 5(6):18-23.

Address for Correspondence

Prof. Hassan A. Al-Shamahy, Department of Basic Sciences, Faculty of Dentistry, Sana'a University, Republic of Yemen., Tel+967-770299847; E-mail: shmahe@yemen.net.ye

\section{INTRODUCTION}

The biofilm consists of any synthetic union of microorganisms in which cells stick to each other and often also to the surface. These adherent cells become embedded within a sticky extra-cellular matrix made up of extracellular polymeric materials (EPSs). Cells within biofilms produce EPS components, which are usually a polymeric conglomeration of sugars, proteins, fats and extracellular DNA ${ }^{1}$. Streptococcus mutans is an elective Gram-positive anaerobic bacteria, alpha hemolytic colonies in blood agar commonly found in the human oral cavity and is a significant contributor to dental caries ${ }^{2,3}$. Dental surfaces colonized with $S$. mutans are more susceptible to caries ${ }^{4}$. In Yemen recent study found that the only $4.6 \%$ of adults were caries free (Score 0) and 249 (95.4\%) presented with caries (Score 1-3) with significant grow in the rate of $S$. mutans heavy colonization with growing caries score ${ }^{5}$. In subpopulations with a moderately high caries occurrence, a positive relationship between saliva levels of $S$. mutans and the occurrence of dental 
caries ${ }^{6,7}$ has been reported. Those with high levels of $S$. mutans as well arise coronary and root caries in impermanent and permanent restorations than those in the similar population with a lower concentration of $S$. mutans $^{8,9}$. The salivary levels of $S$. mutans were studied to see if there was a direct relationship to the heavy colonization of $S$. mutans and their ratio in the formation of dental plaque ${ }^{10}$. However, there is limited information on the possible relationship between the capability of salivary streptococcus mutans to form biofilms and its ratio in the formation of dental plaque. Dental caries has been described as an environmental impact in the mouth, including infectious bacteria and the promptly available sugar in foods and drinks. Streptococcus mutans has been reported as a major causative agent of normal static plaque and dental cavities $^{10,11}$. The role of biofilms in dental caries has been studied in a limited way. The researchers found that the etiology of dental caries is well recognized and it appears that bacterial colonization is a significant step for oral illness, which leads to the formation of biofilms ${ }^{2,12,13}$. Oral biofilms predominantly comprise multiple bacterial strains. It has recently been demonstrated that more than 700 bacterial strains are present in dental plaque ${ }^{14}$. The potential mechanism of biofilm formation is that $S$. mutant produces glucosyltransferase on the bacterial cell wall, which permits bacteria to generate from sucrose polysaccharides. These adhesive polysaccharides are accountable for the capacity of bacteria to clump together and stick to tooth enamel, forming biofilms. The use of an anti-cellular glucosyltransferase (CA-gtf) immunoglobulin Y disrupts the ability of $S$. mutans to stick on tooth enamel, thus inhibiting it from reproducing. Studies have revealed that Anti-CA-gtf IgY is capable to efficiently control $S$. mutans in the oral cavity ${ }^{15,16,17}$. The expansion of bacterial pathogens resistance to regular antibiotics use has turned into an universal human apprehension. The extend of antibiotic resistance is reason of deaths as well as significant financial problem. In countries with a low economy like Yemen, antibiotic resistance is more prevalent than in developed countries ${ }^{15}$. S. mutans is moreover integrated as a causative agent of endocarditis. Information about knowledge of antibiotics for $\mathrm{S}$. mutans is important for prescribing appropriate treatment in the case of endocarditis ${ }^{18,19}$. The American Heart Association suggests that one hour before the dental procedure, preventive antimicrobial therapy should be given to high-risk cardiovascular patients, such as amoxicillin $(2 \mathrm{~g})$ as a first choice and clindamycin $(600 \mathrm{mg})$ as a second choice ${ }^{17}$. However, beta-lactamase production is unusual for most streptococci, as resistance occurs via a slight change in penicillin binding proteins ${ }^{20,21,22}$. Thus, more information is required concerning the distribution of S. mutans biofilms formation strians and correlation of levels of $S$. mutans biofilms formation with caries in adult females. The present study was planned in an adult population of Sana'a city, in Yemen (i) to determine the $S$. mutans biofilms formation levels in their stimulated saliva and (ii) to correlate the dental caries in these individuals with their relation to $S$. mutans biofilms formation and scores of dental caries. Also to reveal antibacterial sensitivity to isolated $S$. mutans and to study the relationship between biofilm formation and antibiotic resistant.

\section{SUBJECTS AND METHODS}

The current study was carried out in the Department of Medical Microbiology Faculty of Dentistry, Sana'a University. The study proposal was permitted by the ethics committee of the Faculty. A written informed consent was taken from the chosen participants.

\section{Study participants}

The third and fourth authors visited the families of the study sample members residing in the various sectors of Sana'a city. Females between 25 and 35 years of age were selected and the purpose of the study explained. The sample size required for the study was calculated on the basis of the prevalence of caries in adult females obtained on the basis of a pilot study of 50 subjects and a statistical consultation. The inclusion criteria were that the participants were elderly, had no systemic debilitating disease, and had not taken or had taken antibiotics in the past three months. Individuals who underwent orthodontic treatment with dentures, crowns, or bridges were not included in the study. Thus, the interested participants were randomly selected to form a study group of 261 adult females. The selected individuals were instructed not to eat/drink, brush their teeth, use mouthwash, or smoke one hour before their appointment. Households were reviewed by author (AM) on time and tooth decay was recorded and saliva sample collected. Prior to the commencement of the studies, the Registrar (AM) was trained through frequent calibration sessions conducted in the faculty department.

\section{Tooth decay recording}

All study females were examined by the same examiner. Calibration was performed within the examiner regarding the diagnostic criteria for dental caries. The Silness-Loe maternal plague index ${ }^{23}$ was performed. This indicator is based on the study participants' field clinical examination using probe, mirrors and cotton rolls, in addition to simply counting the number of decayed and missing teeth (due to caries only) and restored teeth.

\section{Salivary analysis}

\section{Method of saliva collection}

After the clinical examination, the date for saliva collection was determined. Participants were forced to swallow their pre-existing saliva, in order to clear the mouth of any remaining un-stimulated saliva. Then, each participant chewed a standard piece of paraffin wax for 5 minutes to stimulate the production of saliva that needs to be collected. The saliva samples of all participants were categorized using a code number during the sample collection and processing period.

\section{Microbiological procedure}

The sample was collected and transferred to the laboratory immediately in a thioglycolate culture medium and processed on the same day. The sample was then rotated (15 s) and diluted 1: 1000 in isotonic saline before inoculation. One loop $(1 / 1000 \mathrm{ml}$ of 
sample) was inoculated on the culture medium Mitis salivarius agar with potassium tellurate, bacitracin and $20 \%$ sucrose. Plates were incubated at $37^{\circ} \mathrm{C}$ anaerobically. Streptococci mutans were detected in $251(96.2 \%)$ saliva samples. The detected streptococci mutant were then tested for biofilm formation ability and antibiotic sensitivity.

Biofilm production detection

The biofilm was detected by the tissue culture method/microtiter plate method (TCA) ${ }^{24,25}$. S. mutans isolates were inoculated from fresh agar plates in $2 \mathrm{~mL}$ of Brain Heart Infusion (BHI) broth and incubated for $24 \mathrm{~h}$ at $37^{\circ} \mathrm{C}$. Then the cultures were diluted 1:40 with fresh medium (BHI broth with $1 \%$ glucose added); 200 $\mu \mathrm{l}$ of the sample was dispensed in the individual microtitration plate and incubated further $24 \mathrm{~h}$ at $37^{\circ} \mathrm{C}$ anaerobically. The content was removed again with subsequent washing with phosphate saline $(\mathrm{pH} 7.2)$ three times to remove free-floating sessile bacteria with gentle pecking - then the adherent bacteria, a biofilm product, was fixed with sodium acetate $(2 \%)$ and stained with crystal violet $(0.1 \% \mathrm{w} / \mathrm{w})$. Volume $)$ for 10-15 minutes. The liberated violet crystal solution was removed with triplicate wash with $\mathrm{PBS}$, and then the plate was kept for drying. Finally, with $200 \mu$ l ethanol (95\%) all wells were filled to release the dye from the well and at the wavelength of $630 \mathrm{~nm}$ the optical density (OD) was performed. The OD value was calculated for each negative test and control strain, and the OD cutoff values (ODc) were evaluated as previously described ${ }^{25}$.

\section{Antibiotic sensitivity}

The antibiotic sensitivity profile was determined by the disc diffusion method. Inoculations were adjusted to match the turbidity of $0.5 \mathrm{McF}$ arland criteria, swabbed on Brian Heart infusion agar and left to dry for 10 minutes $^{26}$. The antibiotics employed in this study

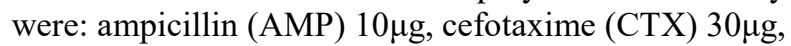
penicillin-G (P) 10 units, erythromycin (E) 15 $\mu \mathrm{g}$, methicillin (MET) $5 \mu \mathrm{g}$, lincomycin (L) $2 \mu \mathrm{g}$, cefazolin (CZ) $30 \mu \mathrm{g}$, vancomycin $\mathrm{V}(30 \mu \mathrm{g})$ and clindamycin (CC) $2 \mu \mathrm{g}$ (Oxide, USA). The zone of inhibition was measured after $24 \mathrm{~h}$ of anaerobic incubation at $37^{\circ} \mathrm{C}$. Each antibiotic was tested in triplicate. The results were interpreted according to the methodology of the Clinical and Laboratory Standards Institute (CLSI) ${ }^{27}$.

Statistical analysis

Statistical analysis: Epi Info version 7 was used for analysis data. Difference in proportions and associated odds ratio and test of significance were calculated using 2X2 tables and selected uncorrected statistical test for chi square and 2 tailed $\mathrm{p}$ values for significance. Level of statistical significance was assumed at $p<0.05$.

Table 1: Biofilm detection by TCP method for $S$. mutans isolated from adult females.

\begin{tabular}{|c|c|c|}
\hline Biofilm formation & Number & Percentage \\
\hline High* & $31 / 255$ & 12.2 \\
\hline Moderate * & $46 / 255$ & 18.0 \\
\hline Total biofilm & $77 / 255$ & 30.2 \\
\hline Non/weak & $184 / 255$ & 72.2 \\
\hline $\begin{array}{l}\text { Total } S . \text { mutans } \\
\text { isolates }\end{array}$ & $255 / 261$ & 97.7 \\
\hline $\begin{array}{l}\text { Total saliva cultured } \\
\text { specimens }\end{array}$ & 261 & 100 \\
\hline
\end{tabular}

Table 2: The association between biofilm formation of $S$. mutans with Silness-Loe indix for dental caries for adult mothers.

\begin{tabular}{lcccccc}
\hline Index & \multicolumn{2}{c}{$\begin{array}{c}\text { Positive Biofilm } \\
\text { N=77 }\end{array}$} & OR & 95\% CI & $\mathbf{X}^{\mathbf{2}}$ & P \\
\cline { 2 - 3 } & $\mathbf{N o}$ & \% & & & & \\
\hline Score $0 \mathrm{n}=12$ & 0 & 0 & & Undefined & 5.4 & 0.01 \\
Score $1 \mathrm{n}=120$ & 25 & 20.8 & 0.4 & $(0.2-0.7)$ & 9.4 & 0.002 \\
Score $2 \mathrm{n}=90$ & 34 & 37.8 & 1.3 & $0.77-2.3$ & 1.1 & 0.28 \\
Score $3 \mathrm{n}=39$ & 18 & 46.2 & 2.2 & $1.1-4.8$ & 5.5 & 0.01 \\
Total $\mathrm{n}=261$ & 77 & 29.5 & & Undefined & 6.7 & 0.009 \\
\hline
\end{tabular}

\section{RESULTS}

The study, which included 261 saliva samples subjected to bacteriological culture of $S$. mutans isolate, showed $255(97.7 \%)$ significant growth in $S$. mutans. When isolated $S$. mutans were exposed to biofilm detection by TCP method, $31(12.2 \%)$ showed high biofilm formation capacity, $46(18 \%)$ showed moderate biofilm formation capacity, while 184 (72.2\%) showed non/weak formation capacity of biofilm. The overall rate of biofilm formation was $30.2 \%$ (Table 1). There was an escalation in the rate of formation of $S$. mutans biofilms with an increased degree of caries index (Table 1). Overall, 12 (4.6\%) of the females were caries-free (Score 0) and 249 (95.4\%) of the females had caries (Score 1-3). With regard to study females who underwent caries; 120 (45.9\%) got score $1,90(34.5 \%)$ got Score 2 and only 39 (14.9\%) got Score 3, moreover, there was a significant increase in the ability of $S$. mutans biofilms formation with an increasing degree of decay. For example in score 1, $20.8 \%$ of $S$. mutans isolated had positive biofilm formation, in score $2,37.8 \%$ of $S$. mutans isolated had positive biofilm formation; and at score $3,46.2 \%$ of isolated $S$. mutans had positive biofilm formation, with significant correlated OR $=2.2,95 \% \mathrm{CI}=1.1-4.8, X^{2}=$ 5.5 and $P=0.01$ (Table 2). Table 3 presented the antibiotic sensitivity pattern of $S$. mutans. The $S$. 
mutans biofilms positive showed a higher rate of resistance than non/weak biofilm formation: ampicillin (28.6\% versus $12.9 \%, p=0.002)$, amoxicillin $(77.9 \%$ versus $18 \%, p<0.0001)$, penicillin $(79.2 \%$ versus $23 \%$, $<0.0001)$, cefotaxime $(32.5 \%$ versus $7.3 \%, p<0.0001)$, cefazolin $(24.7 \%$ versus $12.9 \%, P=0.019)$, methicillin (27.2\% versus $12.4 \%, p=0.002)$, Lincomycin $(81.8 \%$ versus $30.3 \%, p<0.0001)$, clindamycin $(29.9 \%$ versus $13.5 \%, p<0.0001)$, and erythromycin $(40.3 \%$ versus $26 \%, p=0.02)$. While there was no significant difference between the biofilm formation of $S$. mutans and the non-one in vancomycin resistance (39\% VS $39.3 \%, p=0.96)($ Table 3$)$.

Table 3: Antibacterial resistance pattern of $S$. mutans associated with biofilm formation in $S$. mutans isolated from adult females.

\begin{tabular}{|c|c|c|c|c|c|c|c|}
\hline \multirow[t]{2}{*}{ Antibiotics } & \multicolumn{2}{|c|}{$\begin{array}{c}\text { Total } \\
\mathrm{N}=255\end{array}$} & \multicolumn{2}{|c|}{$\begin{array}{l}\text { Biofilm producing } \\
\text { S. mutans } \mathrm{N}=77\end{array}$} & \multicolumn{2}{|c|}{$\begin{array}{c}\text { Non-Biofilm } \\
\text { producing } S . \text { mutans } \mathrm{N}=178\end{array}$} & \multirow[t]{2}{*}{$\mathbf{P}$} \\
\hline & No & $\%$ & NO & $\%$ & No & $\%$ & \\
\hline Ampicillin & 45 & 17.6 & 22 & 28.6 & 23 & 12.9 & 0.002 \\
\hline Amoxicillin & 92 & 36 & 60 & 77.9 & 32 & 18 & $<0.0001$ \\
\hline Penicillin & 102 & 40 & 61 & 79.2 & 41 & 23 & $<0.0001$ \\
\hline Cefotaxime & 38 & 14.9 & 25 & 32.5 & 13 & 7.3 & $<0.0001$ \\
\hline Cefazoline & 42 & 16.5 & 19 & 24.7 & 23 & 12.9 & 0.019 \\
\hline Methicillin & 43 & 16.9 & 21 & 27.2 & 22 & 12.4 & 0.003 \\
\hline Lincomycin & 117 & 45.9 & 63 & 81.8 & 54 & 30.3 & $<0.0001$ \\
\hline Clindamycin & 47 & 18.4 & 23 & 29.9 & 24 & 13.5 & $<0.0001$ \\
\hline Vancomycin & 100 & 39.2 & 30 & 39 & 70 & 39.3 & 0.96 \\
\hline Erythromycin & 51 & 20 & 31 & 40.3 & 20 & 26 & 0.02 \\
\hline
\end{tabular}

\section{DISCUSSION}

Biofilms are recognized for their formation on many implanted medical devices, comprise: heart valves, catheters, dentures, pacemakers and artificial joints, which provide a superficial and safe haven for the growth of biofilms ${ }^{28}$. The consequences of a devicerelated infection on human health can be severe and life-threatening ${ }^{29}$. In this study, 261 saliva samples subjected to bacteriological culture of $S$. mutans, showed that $97.7 \%$ had significant growth in S. mutans. When isolated $S$. mutans were exposed to biofilm detection by the TCP method, $12.2 \%$ showed a high biofilm formation capacity, $18 \%$ Showed moderate ability to form biofilms, while $72.2 \%$ showed non/weak ability to form biofilms. This high rate of colonization and biofilm production of $S$. mutans in adult females may lead to mouth infections in used subjects or transmission to other parts of the body especially the circulatory system. This suggestion can be confirmed by NHI analysis which indicates that biofilms generally (as well as bacterial and fungal biofilms) are accountable for more than $80 \%$ of all microbial infections ${ }^{28}$. For structural and physiological causes, biofilms are inherently resistant to antimicrobial therapy and host immune defenses. Biofilms cause many infections, ranging from superficial mucosal infections to severe and extensive bloodstream infections. This infection often starts from biofilms on mucous surfaces or implanted medical devices. In the current study, there was an escalation in the rate of formation of $S$. mutans biofilms with an increase in the degree of caries index (Table 1). With regard to study females who underwent caries; 120 $(45.9 \%)$ got score $1,90(34.5 \%)$ got score 2 and only $39(14.9 \%)$ got score 3 , moreover, there was a significant growth in the rate of formation of $S$. mutans biofilms with increasing degree of decay. For example in score $1,20.8 \%$ of $S$. mutans isolated had positive biofilm formation, in score $2,37.8 \%$ of $S$. mutans isolated had positive biofilm formation; and at score 3, $46.2 \%$ of isolated $S$. mutans had positive biofilm formation, with significant association $\mathrm{OR}=2.2,95 \%$ $\mathrm{CI}=1.1-4.8, \quad \mathrm{X}^{2}=5.5$ and $p=0.01$ (Table 2). Dental plaque is an oral biofilm that adheres to the teeth and is made up of many types of bacteria and fungi (such as Streptococcus mutans and Candida albicans), and is an integral part of salivary polymers and extracellular microbial products. Accumulation of microorganisms exposes teeth and gum tissues to high concentrations of bacterial metabolites that lead to dental disease. The biofilm on the surface of teeth is often subjected to oxidative stress and acid stress. Dietary carbohydrates can cause a significant decrease in the $\mathrm{pH}$ of oral biofilms to values 4 and below (acid stress) ${ }^{31-33}$. A pH of 4 at a body temperature of $37{ }^{\circ} \mathrm{C}$ leads to DNA purification, leaving apurinic (AP) sites in the DNA, especially a loss of guanine $\mathrm{si}^{31-33}$.

Dentists usually prescribe most of the antibiotics used in this study ${ }^{34}$. The number of streptococci resistant to oral mutations is greater in people who are frequently exposed to antibiotics, although resistant bacteria may also be found in healthy people who have not been recently treated with antibiotics ${ }^{34}$. $\beta$-lactam antibiotics are the most frequently prescribed chemo prophylactic agent's in general dental practices. In spite of this, penicillin resistance is increased among oral streptococcus $^{35,36}$. The number of resistant oral streptococci is greater in people who are frequently exposed to antibiotics ${ }^{37}$, even though these bacteria can also be established in healthy people who have not been recently treated with antimicrobials ${ }^{38}$. Also, a significant level of penicillin resistance $(40 \%)$ in S.mutant isolates in current study are higher than those of Al-Shami et al., $(14.9 \%)^{36}$ and Pasquantonio et al., $(13.4 \%)^{39}$ to oral streptococcal clinical isolates. Additionally, current result is comparable to the average of a 2014 study by Dhamodhar et al., ${ }^{40} 38 \%$ of $S$. mutans isolates showed complete resistance to penicillin and ampicillin. Production of $\beta$-lactamase is, 
however, unusual for most of streptococci, where resistance is happening by slightly altered of penicillin binding proteins ${ }^{20-22}$. Though, in current study we observed a significant level of amoxicillin resistance [17.6\%) of S. mutans; and $18.4 \%$ for clindimycin. In the current study, in vitro antibiotic sensitivity to various $S$. mutans strains showed that $S$. mutans biofilms positive had a higher rate of resistance to tested antibiotics. This result can be explained by the facts that $S$. mutans positive biofilms are resistant to standard antibiotics for Gram positive bacteria medications due to the availability of biofilms that are considered physical protection of $S$. mutans from medications, as well as cells in biofilms become essentially resistant to drugs due to their changed metabolic states and their constitutive up regulation of drug pumps ${ }^{28}$.

\section{CONCLUSION}

The present study proved that $S$. mutans is still the major bacteria isolate from the oral cavity, but few persons might not have significant number of $S$. mutans in oral cavity. The $S$. mutans biofilm - producers were more able to cause dental caries compared to the $S$. mutans biofilm-non-producers. Drug resistant factor in the $S$. mutans isolates was found to be associated with $S$. mutans biofilm formation. The current study demonstrates significant levels of resistance to penicillin, erythromycin, amoxicillin, clindamycin, and lincomycin in $S$. mutans isolates. Further study is needed to find out the minimum inhibitory concentration of $\beta$-Lactam and non $\beta$-Lactam antibiotics for both biofilm formation $S$. mutans and non- biofilm formation $S$. mutans. These results as well call for enhanced evaluation of antibiotic susceptibility testing for the period of prophylaxis. There is likely to be an alternative to antibiotics such as herbal extract and may be better than antibiotics in the coming years to avoid the coming bacterial resistance to antibiotics. Additionally, the increase in the rate of antibiotic resistance in $S$. mutans isolates suggested that more precautions be taken while prescribing antibiotics will preserve the bacteria with less resistance.

\section{AUTHOR'S CONTRIBUTION}

This research work is part of a Master's thesis. The candidate is Arij Lutf Abdulrhman Abdul Majeed to conduct clinical, laboratory, field work and thesis. Corresponding author (HAA), and other authors supervised the work, revised and edited the thesis draft and the manuscript.

\section{ACKNOWLEDGEMENTS}

Authors acknowledge the financial support of Sana'a University, Yemen.

\section{CONFLICT OF INTEREST}

No conflict of interest associated with this work.

\section{REFERENCES}

1. Aggarwal S, Stewart PS, Hozalski RM. "Biofilm Cohesive Strength as a Basis for Biofilm Recalcitrance: Are Bacterial Biofilms Overdesigned? Microbiol Insights 2016; 8 (Suppl 2): 29-32.

https://doi.org/10.4137/MBI.S31444

2. Al-Shami IZ, Al-Shamahy HA,Abdul Majeed ALA, AlGhaffari KM and Obeyah AA. Association between the salivary Streptococcus mutans levels and dental caries experience in adult females. On J Dent Oral Health 2018; 1(1):1-6. https://doi.org/10.33552/OJDOH.2018.01.000505

3. Hamada S, Slade HD. Biology, Immunology and cariogenicity of Streptococcus mutans. Microbiol Rev 1980; 44:331-84. PMID: 6446023

4. Loesche WJ. The role of Streptococcus mutans in human dental decay. Microbiol Rev 1986; 50:353-80. PMID: 3540569

5. Loesche WJ, Eklund S, Earnest R, Burt B. Longitudinal investigation of bacteriology of human fissure decay; epidemiological studies in molars shortly after eruption. Infect Immun 1984; 46:765-72. https://doi.org/10.1128/IAI.46.3.765-772.1984

6. Emilson CG, Krasse B. Support for an implication of the specific plaque hypothesis. Scand J Dent Res 1985; 93:96-104.

https://doi.org/10.1111/j.1600-0722.1985.tb01316.x

7. Koga-Ito CY, Martins CA, Balducci I, Jorge AO. Correlation among mutans streptococci counts, dental caries, and $\operatorname{IgA}$ to Streptococcus mutans in saliva. Braz Oral Res 2004; 18:350-5.

https://doi.org/10.1590/s1806-83242004000400014

8. Thenisch NL, Bachmann LM, Imfeld T, Leisebach MT, Steurer J. Are mutans streptococci detected in preschool children a reliable predictive factor for dental caries risk? A systematic review. Caries Res 2006; 40:366-74. https://doi.org/10.1159/000094280

9. Preza D, Olsen I, Aas JA, Willumsen T, Grinde B, Paster BJ. Bacterial profiles of root caries in elderly patients. J Clin Microbiol 2008; 46:2015-21. https://doi.org/10.1128/jcm.02411-07

10. Lenander-Lumikari M, Loimaranta V. Saliva and Dental Caries. Adv Dent Res 2000;14:40-7. PMID: 10553245

11. Lemos A and R the EPS. $0 \mathrm{~kb}$ gene ments in S. at epsA and A Burne. A Microbiol 2008; 15(11):3247-325. https://doi.org/10.4236/aim.2012.23025

12. Busscher HJ, HC van der Mei. Physico-chemical interactions in initial microbial adhesi and relevance for biofilm formation. Adv Dent Res 1997; 11(1):24-32. https://doi.org/10.1177/089593749701100113

13. Meyer DH, PM. Fives-Taylor. Oral pathogen from dental plaque to cardiac disease. Curre Opin Microbiol 1998; 1(1):88-95. https://doi.org/10.1016/S1369-5274(98)80147-1

14. Aas JA, Paster Dewhirst BJ. Defining the Normal bacterial floara of the Oral Cavity. J Clin Microbiol 2005; 43(11): 5721-5732. https://doi.org/10.1128/JCM.43.11.5721-5732.2005

15. Stewart PS, Costerton JW. Antibiotic resistance of bacteria in biofilms. Lancet 2001; 358 (9276): 135-8. https://doi.org/10.1016/S0140-6736(01)05321-1 PMID 11463434. S2CID 46125592.

16. Del Pozo JL, Rouse MS, Patel R. Bioelectric effect and bacterial biofilms. A systematic review. The International J Artif Org 2008; $31(9)$ : 786-95. https://doi.org/10.1177/039139880803100906

17. Kapi A. The evolving threat of antimicrobial resistance: Options for action. Indian J Med Res 2014; 139(1):182. https://apps.who.int/iris/handle/10665/44812

18. DeMoor CE, DeStoppelaar JD, Van Houte J. The occurrence of $S$. mutans and $S$. sanguis in the blood of endocarditis patients. Caries Res 1972; 6:73.PMID: 4502189 
19. Dajani AS, Taubert KA, Wilson W. Prevention of bacterial endocarditis. Recommendations by the American Heart Association. J Am Dent Assoc 1997; 96: 358-366.

https://doi.org/10.14219/jada.archive.1997.0375

20. Chambers HF. Penicillin-binding protein-mediated resistance in Pneumococci and Staphylococci. J Infect Dis 1999; 179: S353-359.https://doi.org/10.1086/513854

21. Cvitkovitch DG. Genetic competence and transformation in oral streptococci. Crit Rev Oral Biol Med 2001; 12: 217-243.

https://doi.org/10.1177/10454411010120030201

22. Hakenbeck R. Mosaic genes and their role in penicillin resistant Streptococcus pneumoniae. Electrophoresis 1998; 19: 597-601.

https://doi.org/10.1002/elps.1150190423

23. Al-Shami IZ, Al-Shamahy HA, Abdul Majeed ALA, AlGhaffari KM and Obeyah AA. Association between the salivary Streptococcus mutans levels and dental caries experience in adult females. On J Dent Oral Health 2018; 1(1):1-6.

https://doi.org/10.33552/OJDOH.2018.01.000505

24. Christensen GD, Simpson WA, Bisno AL, Beachley EH. Adherence of slim-producing strains of Staphylococcus epidermidis to smooth surfaces. Infect Immunity 1982; 37(1):318-326. PMID:6179880

25. Stepanovic S, Vukovic D, Hola V, et al. Quantification of biofilm in microtiter plates: overview of testing conditions and practical recommendations for assessment of biofilm production by Staphylococci. Acta Patho Micro 2007; 115(8):891-899. https://doi.org/10.1111/j.1600-0463.2007.apm 630.x

26. Jebashree HS, Kingsley SJ, Sathish ES, Devapriya D. Antimicrobial activity of few medicinal plants against clinically isolated human cariogenic pathogens: An in vitro study. ISRN Dent 2011; 11: 67-72. https://doi.org/10.5402/2011/541421

27. CLSI. Performance Standards for Antimicrobial Disc Susceptibility Tests. (11 $1^{\text {th }}$ edn.), Approved standard M02-A11- Publication of Clinical and Laboratory Standards Institute [CLSI), 2012; USA, 32.

28. Donlan RM, Costerton JW. Biofilms: survival mechanisms of clinically relevant microorganisms. Clin Microbiol Rev 2002; 15:167-93; PMID:11932229 https://doi.org/10.1128/CMR.15.2.167-193.2002

29. Donlan RM. Biofilm formation: a clinically relevant microbiological process. Clin Infect Dis 2001; 33:138792. https://doi.org/10.1086/322972
30. Fox EP, Nobile CJ. A sticky situation, Transcription 2012; 3:6, 315-322. https://doi.org/10.4161/trns.22281

31. Augustin M, Chifiriuc CB, Lazăr V, Stănescu R, Burlibaşa M, Ispas DC. Microbial biofilms in dental medicine in reference to implanto-prostethic rehabilitation". Revista de Chirurgie Oro-maxilo-facială și Implantologie 2010; 1 (1): 9-13. https://doi.org/10.1515/rrlm-2017-0001

32. Marquis RE. Oxygen metabolism, oxidative stress and acid-base physiology of dental plaque biofilms. J Indust Microbiol 1995; 15 (3): 198-207. https://doi.org/10.1007/bf01569826

33. Lemos JA, Abranches J, Burne RA. Responses of cariogenic streptococci to environmental stresses. Curr Iss Mol Biol 2005; 7 (1): 95-107. PMID 15580782

34. Salman HA, Senthikumar R. Identification and antibiogram profile of Streptococcus mutans and Streptococcus sobrinus from dental caries subjects. Contemp Clin Dent 2017; 5(06): 054-057. https://doi.org/10.7324/JAPS.2015.50608

35. European Committee on Antimicrobial Susceptibility Testing [EUCAST). Clinical breakpoints 2010.

36. Al-Shami IZ, Al-Hamzi MA, Al-Shamahy HA, et al. Efficacy of some antibiotics against Streptococcus mutans associated with tooth decay in children and their mothers. On J Dent Oral Health 2019;2(1): 1-6. https://doi.org/10.33552/OJDOH.2019.02.000530

37. Escribano E, Linares J, Alcaide F, Alonso T, Ayats J, et al. Increasing antimicrobial resistance among blood isolates of viridans Streptococcus. Program and abstracts of the $30^{\text {th }}$ Inter-science conference on Antimicrobial Agents and Chemotherapy. American Society for Microbiology 1990; Washington DC, USA.

38. Tozer RA, Boutflower S, Gillespie WA. Antibiotics for the prevention of bacterial endocarditis during dental treatment. Lancet 1966; 1: 686-688. https://doi.org/10.18773\%2Faustprescr.2017.054

39. Pasquantonio G, Condo S, Cerroni L, Bikiqu L, Nicoletti $\mathrm{M}$, et al. Antibacterial activity of various antibiotics against oral Streptococci isolated in the oral cavity. Int $\mathbf{J}$ Immunopathol Pharmacol 2012; 25(3): 805- 809 https://doi.org/10.1177/039463201202500331

40. Dhamodhar P, Sreenivasa M, Channarayappa, Shanthakumar SS, Indiresha HN. Prevalence, characterization and heterogeneity studies on Streptococcus mutans isolated from Bangalore urban population. Int J Pharm Bio Sci 2012; 5(3): 122-128. 